\title{
EL PROFESOR ENRIQUE BALCELLS ROCAMORA
}

\author{
JOSÉ M. GARCÍA RUIZ
}

Profesor de Investigación del CSIC Instituto Pirenaico de Ecología

El Dr. Enrique Balcells Rocamora falleció en la madrugada del día 5 de febrero de 2007 en Jaca (Huesca), donde había contribuido de forma decisiva a la creación y consolidación del Instituto Pirenaico de Ecología. Su fallecimiento ocurrió en un momento en que este número de la revista Cuadernos de Investigación Geográfica estaba en la fase de "pruebas de imprenta", lo que ha facilitado la inclusión de esta nota necrológica gracias a la sensibilidad de su Director, el Dr. José Arnáez Vadillo. No en vano, el Dr. Balcells perteneció durante muchos años al Consejo Científico de la revista. Por otra parte, su estrecha vinculación con el mundo de la Geografía justifica la inclusión

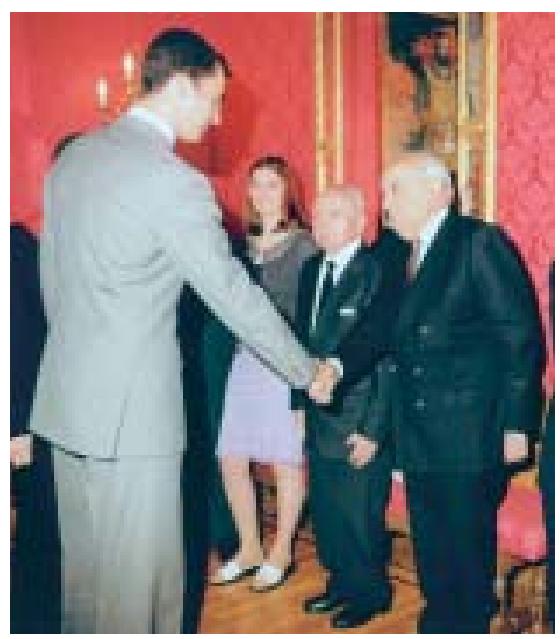
urgente de este modesto homenaje a su persona y un apresurado recuerdo de algunos momentos especialmente relevantes en lo personal y en lo profesional.

El Dr. Balcells entra en la historia de la ciencia española como uno de los científicos de mayor importancia en la evolución reciente de los estudios de Ecología en España. Había nacido en Barcelona en 1922, obtuvo el título de Licenciado en Ciencias Naturales por la Universidad de Barcelona en 1943 y se doctoró en la Universidad de Madrid en 1950. Su primera dedicación científica estuvo claramente volcada hacia el campo de la zoología, con frecuentes estancias en el Museo de Zoología de Ginebra, la Cátedra de Anatomía Comparada de la Sorbona, los laboratorios de vertebrados del Museo de Historia Natural de París y el Instituto Zoológico de la Universidad de Basilea. Los trabajos publicados durante los años cincuenta y sesenta sobre aspectos faunísticos y ecofisiológicos, así como anatomía y fisiología del desarrollo se consideran hoy, muchos años después, aportaciones fundamentales para el desarrollo de la zoología española. Ya para entonces había iniciado el estudio de espacios protegidos, como es el caso del Parque Nacional de Aigües Tortes. 
Profesor de Investigación del Consejo Superior de Investigaciones Científicas (CSIC), el Dr. Balcells fue además Vicepresidente del antiguo Patronato "Alonso de Herrera" de este organismo. Actuó también como secretario del Comité Español para el Programa Biológico Internacional, Presidente del Comité Español para el Programa Man and Biosphere $(\mathrm{MaB})$ y Académico de la Real Academia de Ciencias y Artes de Barcelona, entre otros reconocimientos. En Jaca, ciudad en la que vivió durante casi 45 años, el Ayuntamiento le concedió el Sueldo Jaqués, distinción reservada a las personalidades que más han contribuido a su desarrollo en distintos campos de la cultura, la economía o la sociedad.

Fue persona decisiva, con el apoyo de D. José María Albareda, entonces Secretario General del CSIC, en la creación del Centro Pirenaico de Biología Experimental en Jaca en el año 1963. Debió ser una experiencia emocionante: un nuevo centro de investigación sobre el medio ambiente y el hombre en las áreas de montaña, el diseño de las diferentes líneas de investigación, ver el futuro más que el presente, imaginar lo que ese centro podría ser con suficientes medio materiales y humanos, ajeno a trabas burocráticas. Con el entusiasmo con que, años después, nos contaba a algunos jóvenes, seleccionó a un reducido número de licenciados a los que encaminó por el campo de la zoología (Juan Pablo Martínez Rica y Juan Ramón Vericad), la ecología forestal (Juan Puigdefábregas) o el Cuaternario reciente (Carlos Martí). Además, contó desde casi el principio con la ayuda de otra personalidad de gran relevancia científica: el Dr. Pedro Montserrat Recoder, también Profesor de Investigación del CSIC, que cubriría el área de la botánica, la ecología vegetal y los pastos. No fueron tiempos fáciles: Puso mucha de su fortuna personal en el empeño y sacrificó su vida, en el sentido más amplio de la palabra, en superar los muchos obstáculos a los que tuvo que enfrentarse el nuevo centro de investigación y también en la formación de los jóvenes becarios. No siempre fue comprendido en su justa medida, como sucede con quienes quieren superar una frontera y abrirse a nuevos horizontes que, finalmente, también pueden quedarse cortos. Fue Director del Centro Pirenaico de Biología Experimental hasta 1985, cuando muchos de sus planteamientos habían quedado agotados, no tanto en el fondo como en su expresión formal.

Desde 1968 fue además director del Instituto de Estudios Pirenaicos, también del CSIC y fundado en Jaca en 1942, ligado hasta entonces al Departamento de Geografía de la Universidad de Zaragoza y trasladado de nuevo a Jaca para reforzar el papel científico de esta localidad en los estudios sobre el Pirineo y de las montañas del mundo. El Instituto de Estudios Pirenaicos, de carácter inicialmente multidisciplinar, motivó al Dr. Balcells a abrir nuevas líneas de investigación no exclusivamente biológicas. A los estudios sobre paleoambientes del Cuaternario, que deberían servir para explicar muchos aspectos de la dinámica actual de los paisajes o la distribución de especies vegetales y animales, se sumaron los estudios de Geografía Humana, que significaron la incorporación de las sociedades humanas, pasadas y presentes, en la explicación de la estructura y función de los paisajes, y una perspectiva espacial para pasar de los estudios de detalle a las grandes escalas regionales. Conectó también frecuentemente con etnólogos que estaban por encima de la curiosidad descriptiva de los objetos y de las rutinas empleadas en la gestión del territorio, para profundizar más en las razones ambientales de esas 
rutinas. Tenía una formación y una mentalidad enciclopedista, un poco a la manera de los personajes renacentistas para los que el conocimiento de la propia disciplina siempre se quedaba corto, necesitando penetrar en otros campos que amplían la visión de la Ciencia y del Hombre. En ese sentido fue una persona arriesgada, en la frontera entre el éxito y el fracaso, como los grandes científicos, porque, ¿cómo si no puede avanzarse?, y fue también en buena parte incomprendida, porque para comprenderle era necesaria no sólo imaginación, también una mentalidad abierta dispuesta a asumir igualmente riesgos. Una de sus grandes contribuciones a la Ciencia española, quizás la más importante, fue el estudio de las interacciones entre las actividades humanas y sus consecuencias en los ecosistemas de montaña. Concebía el territorio como un espacio complejo en el que se establecen múltiples interferencias de tipo físico y humano, de manera que su dinámica actual no se entiende sin la presencia histórica de las sociedades humanas, adelantándose varias décadas a otras iniciativas. Por su contribución geográfica a la ecología, o ecológica a la geografía, fue investido el día 16 de mayo de 1991 como Doctor Honoris Causa por la Universidad de Zaragoza, a propuesta de su Departamento de Geografía. Su emotivo y profundo discurso fue contestado por el Prof. José Luis Calvo Palacios, quien con su Tesis de Licenciatura sobre el valle de Aísa había abierto desde 1968 puertas que hasta entonces parecían cerradas para los geógrafos.

Su dilatada actividad científica se refleja en más de 200 publicaciones en revistas nacionales y extranjeras y en numerosas monografías. Los trabajos publicados durante los años cincuenta y sesenta sobre aspectos faunísticos y ecofisiológicos, así como anatomía y fisiología del desarrollo se consideran hoy, muchos años después, aportaciones fundamentales para el desarrollo de la zoología española. Pero lo que me interesa resaltar aquí y ahora es su aportación geográfica al conocimiento de los Pirineos. Suya fue la iniciativa de elaborar una monografía sobre la vida rural en la montaña española (Anglada et al., 1980), en la que se definieron los rasgos básicos de las áreas de montaña, la evolución reciente de la organización social y de los sistemas de explotación de las montañas ibéricas y se establecían algunos principios para una futura ley de montaña. Fue un libro elaborado en muy poco tiempo, gracias a sus orientaciones y al enorme entusiasmo que nos contagió a los coautores. He tenido ocasión de revisar ahora lo escrito hace más de 25 años y he quedado sorprendido con la frescura de algunas ideas que no hemos sido capaces de explotar en su totalidad. También he recordado mi Tesis Doctoral (García Ruiz, 1976), que tanto debe a conversaciones mantenidas caminando despacio por el largo pasillo del edificio que albergaba al Instituto en Jaca, en el que yo atrapaba frases a vuelapluma, ideas perdidas entre frases complejísimas que sólo los más iniciados podían interpretar. Me dedicó muchas horas porque creía en lo que hacíamos los geógrafos y siempre he agradecido el tiempo que, desinteresadamente, empleó en mi formación. Quizás por influencia de Eugenio de Mingo, vivía obsesionado por el Prepirineo, sus paisajes degradados, la despoblación y la ruina de sus pueblos, la pérdida de los usos más adaptados a las duras condiciones ambientales. En el recuerdo queda también la Tesis Doctoral de Teodoro Lasanta (Lasanta, 1989) sobre la evolución reciente de la agricultura en el Pirineo aragonés, de la que fue director. El Dr. Balcells entendió bien la necesidad de abordar el estudio de uno de los pilares en la transformación del paisaje pirenaico y en la 
organización de su economía y sociedad: la agricultura ha sido la excusa más importante para la transformación de las laderas y fondos de valle, y un pilar básico para entender los modelos de gestión de la ganadería. El paisaje actual del Pirineo, y de todas las montañas mediterráneas, no puede entenderse sin profundizar en los modelos de campos, su aprovechamiento, la integración entre agricultura y ganadería, los grandes cambios de uso del suelo o los conflictos que la competencia por el uso de los fondos de valle generan otros aprovechamientos más modernos.

Por sugerencia de Antonio y Julia López Gómez sacó adelante un volumen monográfico de la revista Estudios Geográficos (número 153, 1978) sobre el Pirineo, donde incluyó un artículo de síntesis dedicado a la montaña como reserva que condensa muchas de sus ideas sobre la ecología de las áreas de montaña y su utilización (Balcells, 1978). Fue una iniciativa valiente pero sabía que contaba con el respaldo de algunos de sus incondicionales (Carlos Martí, Juan Puigdefábregas, José Creus y el autor de este escrito). Más recientemente (Balcells, 1998), se enfrentó a una obra monumental de uno de los territorios mejor conocidos y amados por él, el Parque Nacional de Ordesa y Monte Perdido, que estuvo visitando todos los miércoles con Enrique Ejarque hasta muy recientemente. Es quizás el trabajo que culmina su actividad científica, volcando en sus páginas de forma altruista todo lo que sabía sobre el Parque y apuntando un poco de lo mucho que sabía sobre las montañas en general y sobre el Pirineo en particular. No es un libro de lectura fácil, porque nada hacía fácil. Pero contiene una información inmensa que sólo los ignorantes pueden menospreciar. En cada página hay ideas e intuiciones que pueden ser todavía hoy explotadas para dar explicación a la distribución de especies, al peso de las diferentes actividades humanas en la evolución del paisaje y las complejas adaptaciones de los aprovechamientos agroganaderos a la heterogeneidad de la montaña. En relación con la ganadería, tenía motivos para saber más de lo imaginable (Puigdefábregas \& Balcells, 1966; García Ruiz \& Balcells, 1978). Su carácter emprendedor y desprendido le llevó a crear una explotación ganadera modélica en la que invirtió mucho tiempo y dinero. Tuvo la iniciativa de fomentar la raza vacuna pirenaica, casi desaparecida a comienzos de los años setenta en el Pirineo aragonés y sirvió de modelo a otros ganaderos posteriores. Con la ayuda inicialmente de Enrique Ejarque y, más tarde, de Alberto Valdelvira ideó un modelo de aprovechamiento muy complejo que tenía en cuenta la diversidad espacio-temporal de los recursos pastorales y de su calidad, complementando los puertos de verano en la alta montaña, con los pastos de menor calidad en el Prepirineo (Pardina de Esporret) y con un aprovechamiento más intensivo en la Depresión Interior Altoaragonesa (Pardina de Samitier). Estaba convencido de que el éxito de la ganadería pirenaica residía en el uso extensivo de los recursos y en su complementariedad, contando además con espacios más intensivos que pudieran asegurar la alimentación del ganado en determinados momentos. Fue, con Juan Puigdefábregas, un pionero en el estudio ecológico de la ganadería, como lo prueba el excelente trabajo sobre la organización social y la explotación del territorio en el valle de El Roncal, donde se hizo un pormenorizado balance de todos los aprovechamientos y de las entradas y salidas del sistema agroganadero (Puigdefábregas \& Balcells, 1970). Leí recientemente ese trabajo y aún me parecía nuevo, en condiciones de ser publicado con pocas modificaciones en algunas de las mejores revistas internacionales de Geografía o Ecología. 
En 1985 dejó la dirección del Centro Pirenaico de Biología Experimental y del Instituto de Estudios Pirenaicos, que se fusionaron en uno sólo, el actual Instituto Pirenaico de Ecología. También dejó poco después la dirección de la revista Pirineos, que llevó con cariño durante veinte años, aumentando su prestigio y su difusión. Después de su jubilación en 1991 continuó trabajando como siempre en su despacho, con el apoyo de Jesús Mairal, participando en el Patronato del Parque Nacional de Ordesa y Monte Perdido, escribiendo nuevos artículos e informes y dando consejos a quienes mantenían con él una relación de afecto que realzaba sus muchas virtudes personales. Fue un hombre generoso en extremo al volcar toda su vida en los sueños inalcanzables que caracterizan a los grandes científicos y en la formación de quienes fuimos jóvenes y creímos en lo que él nos inculcaba: el rigor y el entusiasmo, la necesidad de abrir nuevas líneas de trabajo que nos dieran explicación a la complejidad de los sistemas naturales. Yo lo conocí hace muchos años, primero en febrero de 1970, con ocasión de una excursión organizada por el Departamento de Geografía de la Universidad de Zaragoza al Pirineo, y después durante un curso de campo organizado por el Instituto de Estudios Pirenaicos y dirigido por José Luis Calvo Palacios en el valle de Aragüés. En ambos casos quedé atrapado por el proyecto científico del Dr. Balcells, por la ruptura que representaba respecto a lo que yo me creía capaz de hacer. En enero de 1971 tuve la suerte de que el Profesor Antonio Higueras me pusiera en contacto con él para hablar de una posible Tesis Doctoral sobre Geografía Humana. Me recibió como hacía con todo el mundo, cualquiera que fuera su importancia personal o profesional. Tenía entonces casi 49 años y me parecía una persona extremadamente respetable y respetada. Me alojé en su casa y estuvimos hablando, en esa ocasión y en otras posteriores, hasta muy tarde, con un vino de nueces (ratafía) que yo desconocía entonces pero que todavía preparo en su recuerdo a finales de junio de algunos años. Me contó muchas historias prepirenaicas y me llevó, acompañado de Manuel Mairal, hasta Longás, un pueblo prototípico del Prepirineo más profundo, donde temporalmente tenía un gran rebaño de ovejas. Conmigo fue exquisito en el trato y siempre he estado agradecido a sus consejos y al tiempo que, quizás inmerecidamente, me dedicó muchos domingos por la tarde cuando él caminaba por el largo pasillo del Instituto tratando de descansar después de haber escrito muchos folios de un informe que pocos leerían, o de un artículo que, estoy seguro, contendría muchas ideas contadas con palabras y expresiones antiguas pero que nos llevaban, sin que nosotros lo supiéramos, al futuro.

\section{Referencias bibliográficas}

Anglada, S., Balcells, E., Creus Novau, J., García Ruiz, J.M., Martí Bono, C. y PuigdefábregAs, J. (1980). La vida rural en la montaña española. Instituto de Estudios Pirenaicos, 113 pp., Jaca.

BALCELls, E. (1978). La montaña como reserva. Estudios Geográficos, 153: 443-472. 
BALCELls, E. (1998). Apuntes sobre recursos naturales y utilización del territorio del Parque Nacional de Ordesa y Monte Perdido. Ministerio de Medio Ambiente, 446 pp., Madrid.

GARCía RuIZ, J.M. (1976). Modos de vida y niveles de renta en el Prepirineo del Alto Aragón Occidental. Instituto de Estudios Pirenaicos, 282 pp., Jaca.

GARCÍA RuIZ, J.M. y BALCELls, E. (1978). Tendencias actuales de la ganadería en el Alto Aragón. Estudios Geográficos, 153: 519-538.

LASANTA MARTÍNEZ, T. (1989). Evolución reciente de la agricultura de montaña: El Pirineo aragonés. Geoforma Ediciones, 220 pp., Logroño.

PuigdefÁbregas, J. y BALCELls, E. (1966). Resumen sobre el régimen de explotación ovina trashumante en el Alto Aragón, especialmente en el valle de Ansó. Publicaciones del Centro Pirenaico de Biología Experimental, 1: 18 pp.

PuigdefÁbregAS, J. y BALCELls, E. (1970). Relaciones entre organización social y explotación del territorio en el valle de El Roncal. Pirineos, 98: 53-89. 